\title{
MICROSTRUCTURE AND FATIGUE PROPERTIES OF DISSIMILAR SPOT WELDED JOINTS OF AISI 304 AND AISI 1008
}

\author{
Nachimani Charde \\ Department of Mechanical, Material and Manufacturing Engineering \\ University of Nottingham Malaysia Campus, \\ Jalan Broga, 43500 Semenyih, Selangor Darul Ehsan, Malaysia \\ Tel:+60389248622 Fax: +60389248001 \\ Email: nachi.charde@nottingham.edu.my
}

\begin{abstract}
Carbon steel and stainless steel composites are being more frequently used for applications requiring a corrosion resistant and attractive exterior surface and a high strength structural substrate. Spot welding is a potentially useful and efficient jointing process for the production of components consisting of these two materials. The spot welding characteristics of weld joints between these two materials are discussed in this paper. The experiment was conducted on dissimilar weld joints using carbon steel and 304L (2B) austenitic stainless steel by varying the welding currents and electrode pressing forces. Throughout the welding process; the electrical signals from the strain sensor, current transducer and terminal voltage clippers are measured in order to understand each and every millisecond of the welding process. In doing so, the dynamic resistances, heat distributions and forging forces are computed for various currents and force levels within the good welds' regions. The other process controlling parameters, particularly the electrode tip and weld time, remained constant throughout the experiment. The weld growth was noted for the welding current increment, but in the electrode force increment it causes an adverse reaction to weld growth. Moreover, the effect of heat imbalance was clearly noted during the welding process due to the different electrical and chemical properties. The welded specimens finally underwent tensile, hardness and metallurgical testing to characterise the weld growth.
\end{abstract}

Keywords: Carbon steel welding; stainless steel welding; dissimilar weld joints; mixed steel joints.

\section{INTRODUCTION}

Spot welding mechanisms join two or more metal sheets together at discrete spots through fusion. It is accomplished by pressing two copper electrodes on both sides of the base metals and suppling a huge amount of current (typically kA) through the contact areas of the upper electrode to lower electrode and vice versa (Aravinthan and Nachimani, 2011a). The flow of the current against the sum of the resistive path (electrode-to-sheet resistances, bulk resistance and sheet-to-sheet resistance) causes heat development and the melt starts between the base metals due to the high resistances in the resistive path, and gradually fuses the asperity areas (Chang et al., 2006). As the heat is continuously present due to current flow, the molten areas grow proportionally (Heat, $Q=I^{2} R t$ ) in all directions. When the current flow is stopped, then the molten area will be dried off (Mehdi at al., 2008). The molten and solidified areas of the base metals are thereafter called weld nuggets, and consist of three major zones (Aravinthan and 
Nachimani, 2011a). These are named the fusion zone (FZ), heat affected zone (HAZ) and base metal (BM). The proper joints or bonds between the sheets are usually created in the FZ, and its growth is related to the thermal expansion of the materials (Nachimani, 2012a). Since carbon steel and stainless steel have different thermal expansion rates according to the American Welding Society (AWS) and Welding Technology Institute of Australia (WTIA), the critical diameters are calculated as $4 t^{0.5}$ for carbon steel and $5 t^{0.5}$ for stainless steel ( $t$ represents the thickness in mm). The surrounding areas of the FZs are termed HAZs, and appear due to the thermal conductivity rate of the BMs and the other parts of the BMs remained unchanged. These phenomenon are measured for various current levels and electrode pressing forces with the aid of sensors in an attempt to understand the weld formation.

\section{EXPERIMENTATION}

Welding samples (carbon and stainless steel sheets) were prepared as $200 \mathrm{~mm}$ long by $25 \mathrm{~mm}$ wide from $1 \mathrm{~mm}$ thick sheets. The chemical elements found on stainless steel sheets are: $\mathrm{C}=0.048, \mathrm{Cr}=18.12, \mathrm{Ni}=8.11, \mathrm{Mn}=1.166, \mathrm{Si}=0.501, \mathrm{~S}=0.006, \mathrm{~N}=$ 0.053 and $\mathrm{P}=0.030$; whereas the carbon steel has the chemical elements $\mathrm{C}=0.023, \mathrm{Mn}$ $=0.90, \mathrm{Si}=0.006, \mathrm{~S}=0.050$ and $\mathrm{P}=0.040$. The hardness of the stainless steel was 81.7 $\mathrm{HRB}$ and the hardness of the carbon steel was $65 \mathrm{HRB}$. The sample sheets were welded at their centres with a $60 \mathrm{~mm}$ lap-joint as shown in Figure 1. The electrode tip diameter is given by $D_{E(\mathrm{~mm})}=2.54 \mathrm{~mm}+2 t$; where $t$ is the thickness of one side of metal sheet in millimetres. Hence the diameter of the tip is calculated as $D_{E(\mathrm{~mm})}=2.54 \mathrm{~mm}+2(1 \mathrm{~mm})$ $=4.54 \mathrm{~mm}$; for a $1 \mathrm{~mm}$ thick sheet. A pair of water-cooled copper electrodes with truncated tip-diameters of $5 \mathrm{~mm}$ were used to join these metal sheets, selected from the RWMA's class two (copper and chromium) category. A pair of test samples were initially placed on the top of lower electrode (tip) of the welder, overlaying $60 \mathrm{~mm}$ over each other and then the initiating pedal was pressed. The heating process was started immediately after the squeezing force was achieved, and the welding current was immediately released in accordance with given preset values of welding current, weld time and pressing force. Thereafter the electrode pressing mechanism (pneumaticbased) consumed some time on cold work, and eventually returned to the home position of the upper electrode. These process-controlling parameters (welding current, weld time and electrode pressing force) were established before the welding process started; based on the welding lobe curve. The welding lobe for a welding current versus the electrode pressing force was computed prior to the welding process, and is graphically shown in Figure 2.

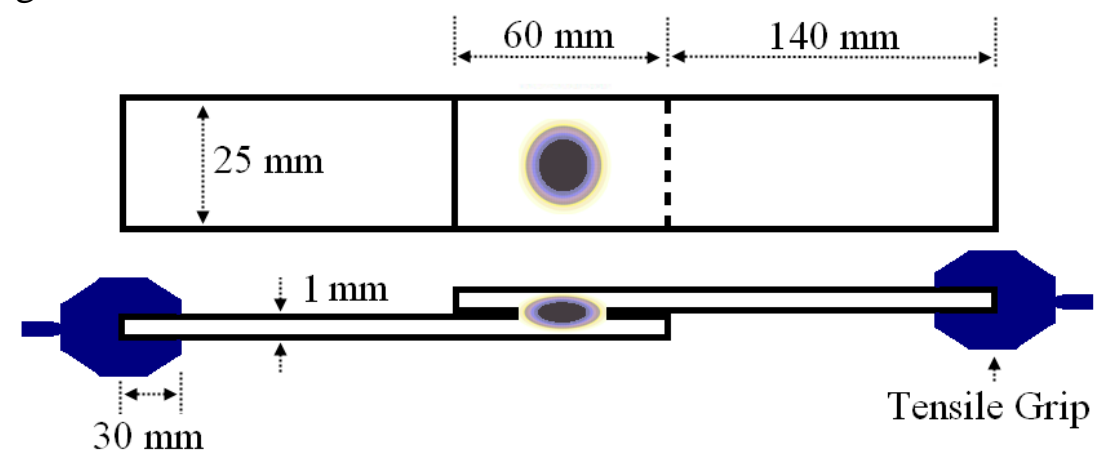

Figure 1. Test sample 


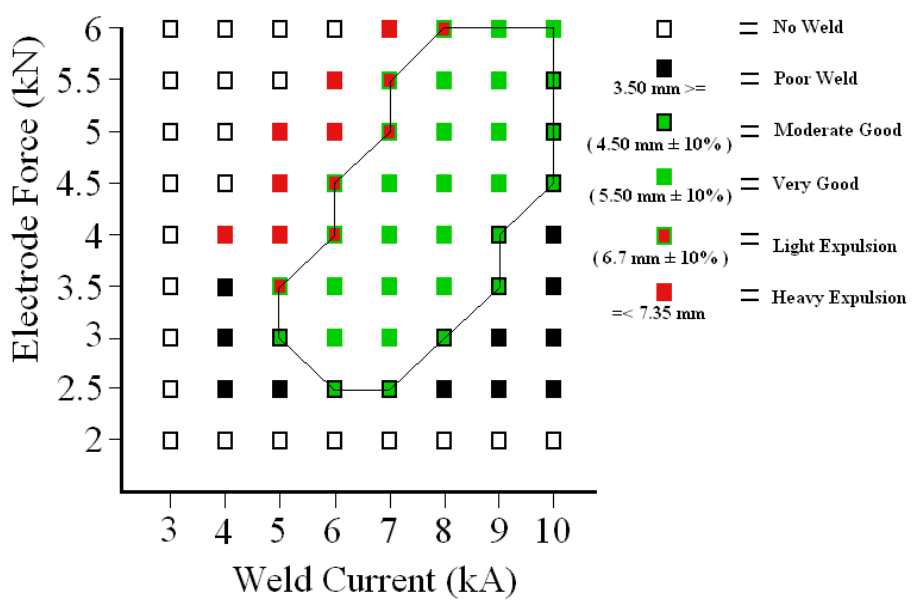

Figure 2. Welding lobe for the welding current versus electrode force

Figure 2 shows the welding lobe curve of the welding current against the welding time for $1 \mathrm{~mm}$ metal sheets after undergoing several welding processes on sample sheets. The lobe boundary is indicated by continuous black lines, which delineates all acceptable welding regions. The coloured symbols represent the quality of the welds produced, and those conditions that did not produce any weld are indicated by white boxes. The green coloured boxes with black borders represent moderate to good welds; the fully green boxes represent very good welds; the red coloured boxes bordered in green represent welds for which light expulsion occurred; the red boxes represent heavy expulsion and the black boxes represent poor welded joints. A weld schedule was finally developed based on the welding lobe curve-bordered regions, in order to avoid expulsion and poor welding conditions, because the scope of this paper is solely to investigate weld growth in good working regions! So the entire welding process is accomplished with three levels of welding current $(6,7,8 \mathrm{kA})$, and for three levels of electrode pressing force $(3,4.5,6 \mathrm{kN})$. Based on these simple computations, nine weld schedules were finalised (Table 1). During the welding process, seven pairs of specimens were welded for each weld schedule. Five out of seven were used for tensile shear testing and the corresponding average value was considered for that particular weld schedule. One pair of specimens was used for hardness testing and the final pair of specimens was used for metallurgical testing.

Table 1. Weld schedule.

\begin{tabular}{llllll}
\hline $\begin{array}{l}\text { Sample } \\
\text { No }\end{array}$ & $\begin{array}{l}\text { Weld } \\
\text { Schedule }\end{array}$ & $\begin{array}{l}\text { Electrode } \\
\text { Tip }\end{array}$ & $\begin{array}{l}\text { Time } \\
(\text { cycle })\end{array}$ & $\begin{array}{l}\text { Current } \\
(\mathrm{kA})\end{array}$ & $\begin{array}{l}\text { Force } \\
(\mathrm{kN})\end{array}$ \\
\hline $1-7$ & 1 & 5 & 10 & 6 & 3 \\
$8-14$ & 2 & 5 & 10 & 7 & 3 \\
$15-21$ & 3 & 5 & 10 & 8 & 3 \\
$22-28$ & 4 & 5 & 10 & 6 & 4.5 \\
$29-35$ & 5 & 5 & 10 & 7 & 4.5 \\
$36-42$ & 6 & 5 & 10 & 8 & 4.5 \\
$43-49$ & 7 & 5 & 10 & 6 & 6 \\
$50-56$ & 8 & 5 & 10 & 7 & 6 \\
$57-63$ & 9 & 5 & 10 & 8 & 6 \\
\hline
\end{tabular}


While performing the welding process, the process parameters (current, voltage and force) were captured using sensors, transducers, and crocodile clips (Shih et al., 2010). The captured signals were then sent through conditioning and amplifying circuits to data analysing software; in this case Signal Express 2010. Figure 3 shows the instrumentation set up for the process parameter reading. This simple set up collected the voltage, current and force waveforms throughout the welding process (Guocheng et al., 2009; Li and Lei, 2011).

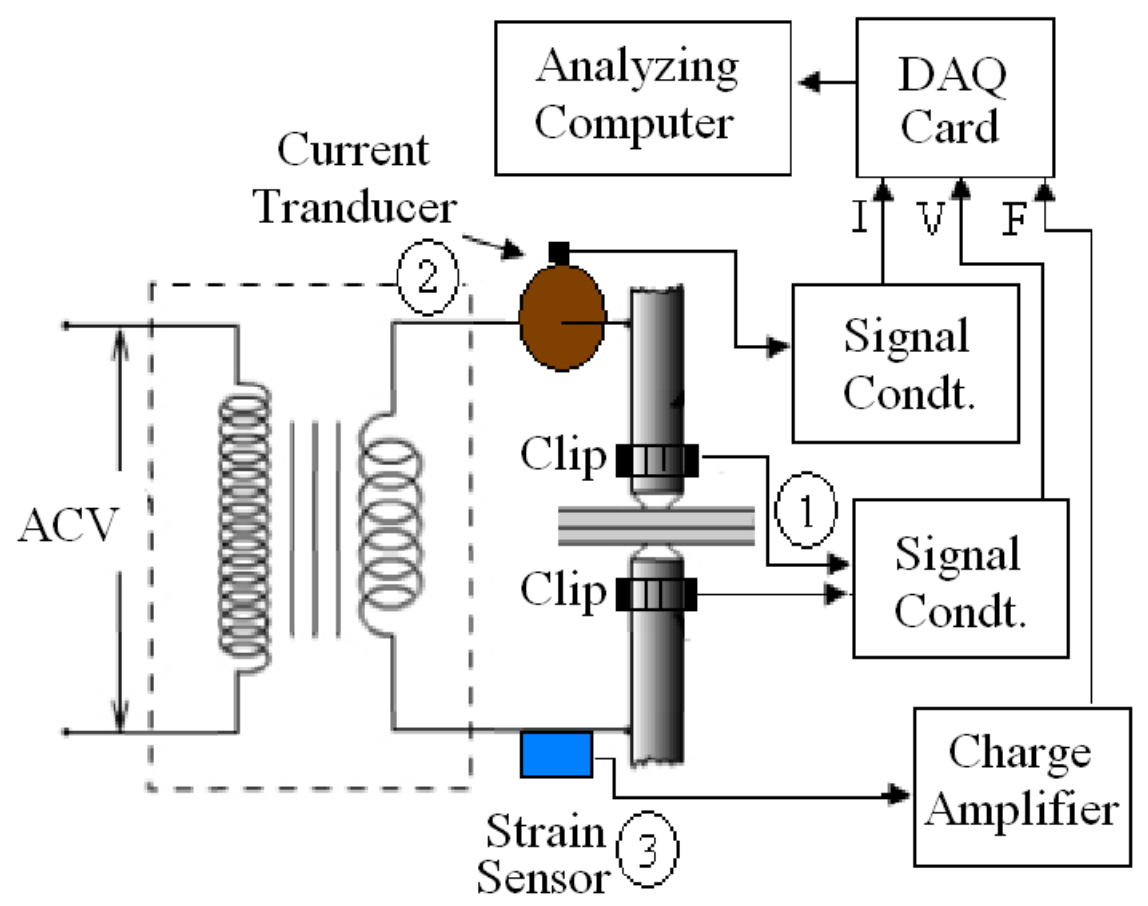

Figure 3. Instrumentation set up for capturing process parameters.

Figure 4 shows a typical force profile of the pneumatic-based electrode actuation for the carbon and stainless steel spot welding process. The squeezing profiles (1) are transient states in which the electrodes are pressing on the metals sheets according to the preset force values. When the pressing force reaches the present value of force, it thereafter holds the electrode with that particular force for the subsequent welding process. If the electrode pressing force is $3 \mathrm{kN}$, then the pneumatically-driven system will press the electrode lever to reach $3 \mathrm{kN}$ during squeezing, and consecutively the welding current will be released. The flow of ahuge amount of welding current causes total atomic imbalances due to high rate of current flow in the welding materials, and triggers some forging effects on the force profiles. The forging forces taking place in the carbon and stainless steels during the welding process are shown in stage 2 of Figure 4. When the welding process is over; the pneumatic-based electrode actuation system holds the upper electrode for a while and finally returns to its home position. The solidification time can also be calculated from this forges in the last stage of the force profiles. 


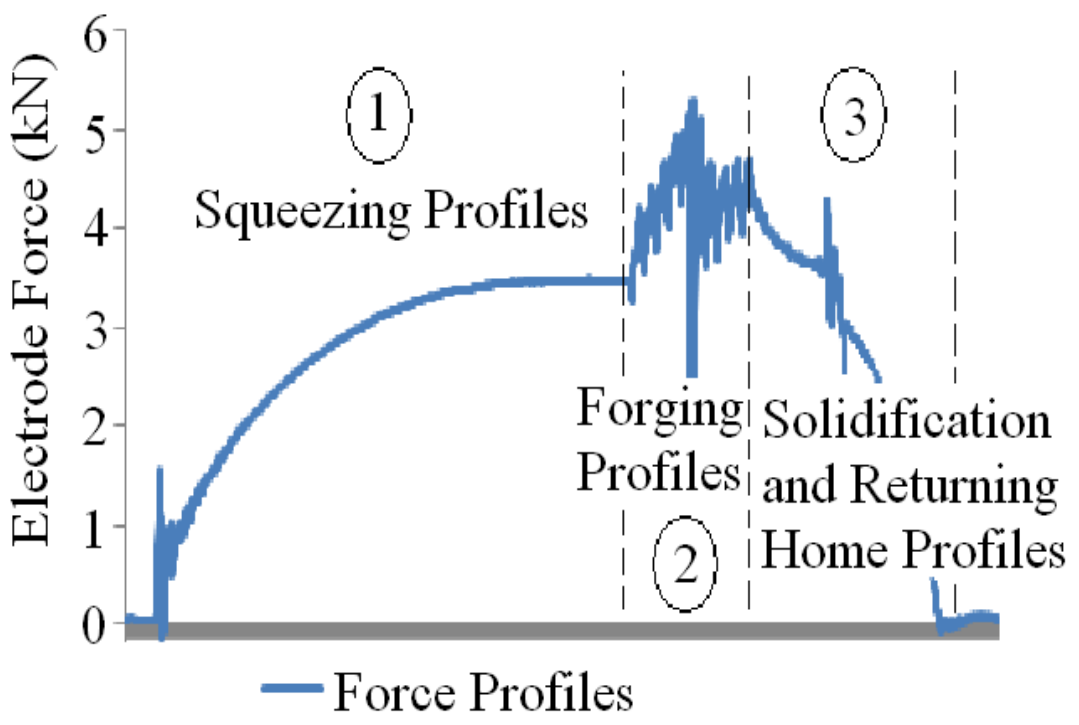

Figure 4. Typical force profile of pneumatic-based spot welder for carbon steel.

Figures 5 and 6 show the current and voltage waveforms captured during the welding process, respectively. These signals are used to compute the dynamic resistances from which the real breakdowns of metals are seen as stages. The dynamic resistance-magnitudes are calculated by $R=V / I$ regardless of the phase shift between signals for a period of 10 weld cycles. Each weld cycle consumes $0.2 \mathrm{mS}$ in real.

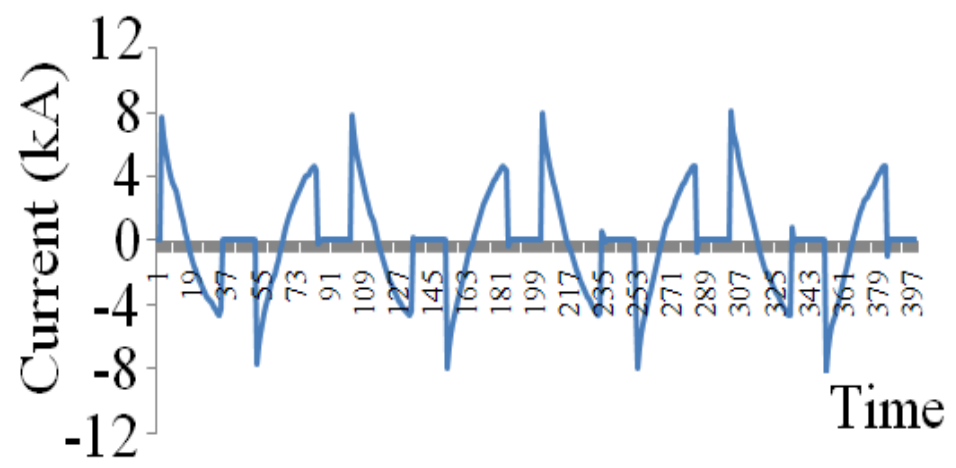

Figure 5. Current waveform after conditioning circuit.

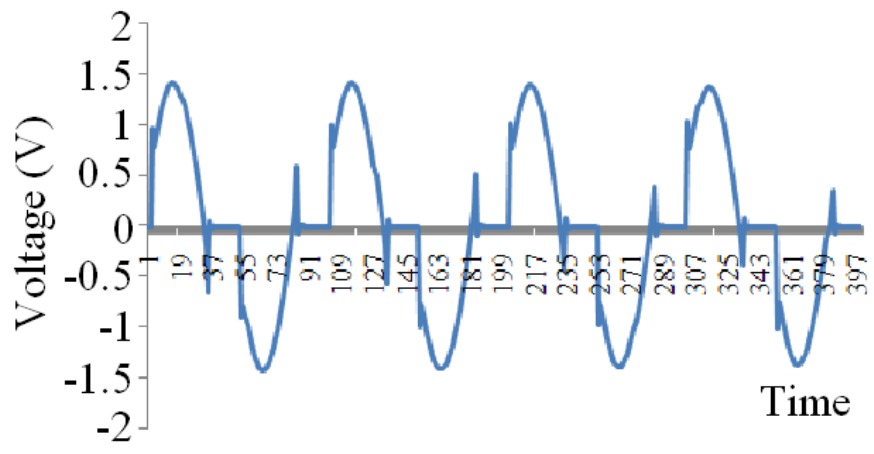

Figure 6. Voltage waveform from conditioning circuit. 


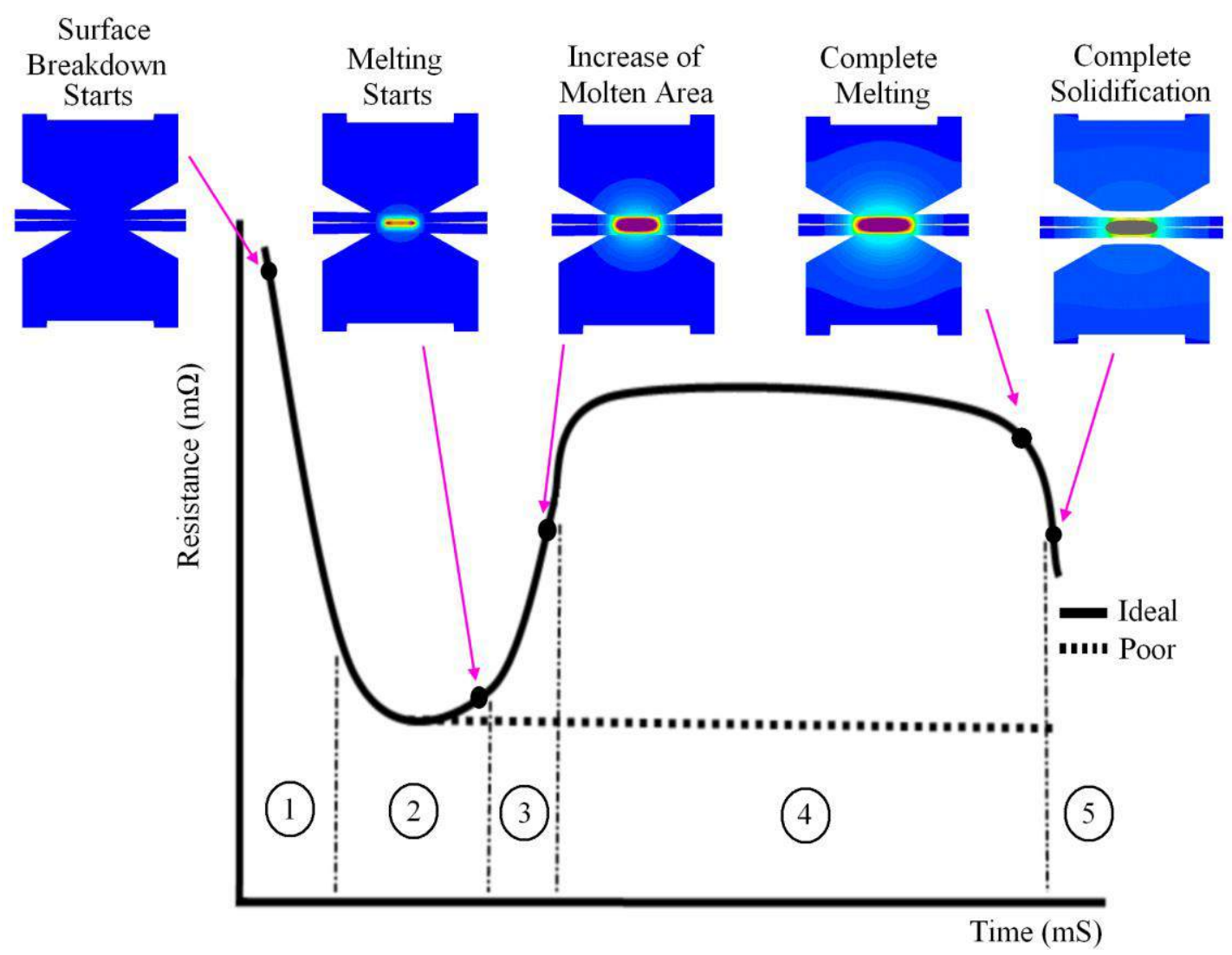

Figure 7. Dynamic resistance patterns.

Figure 7 shows the dynamic resistive pattern proposed by Dickinson (1980) to predict the process resistance during the welding process for good and poor weld joints. Thus the overall dynamic resistive patterns are computed based on this reference model using the current and voltage waveforms of a $75 \mathrm{kVA}$ spot welder. When considering the regions (1, 2, 3, 4 and 5) in Figure 7, region 1 reveals that the impurities on the surface of the BMs cause a high resistance between the electrode tips and metal sheets during the initial current flow, and also act as an insulator. Such sharp drops in resistance are found when a proper contact is established between the electrode tip and metal sheet. Region 2 shows that the contact resistance of the BM s is minimised in this region due to the presence of the current flow. In another words, the contact areas to be welded are well balanced here, and it acts as a reference point to predict the expulsion states from hereon. Likewise, region 3 shows the thermal increment in bulk resistive components (metal resistance) to start the melt process, which will initialise the nugget formation between the faying surfaces of the BM. The following region was numbered 4 , and it finalises the critical weld diameters. In this region the contact resistance is almost minimised, and the temperature appeared to be nearlt constant. Hence the growth of the FZ (diameter) was clearly noted during this stage. Furthermore the following region (region 5) does not fall within the welding process, but in the solidification process. In this stage the liquid metal becomes solid, resulting in micro structural changes due to cold work. A sharp fall in this region or in the middle of an earlier region reveals that an expulsion has occurred. A poor weld joint occurs due to an expulsion as it splashes out the molten metal from the weld nuggets. 


\section{RESULTS AND DISCUSSION}

\section{Force Profiles, Dynamic Resistance and Heat Distribution}

The force profiles of carbon and stainless steels for various current increments $(6,7$ and $8 \mathrm{kA}$ ) during the welding process are shown in Figure 8(a), and the equivalent dynamic resistive changes are shown in Figure 8(b). The circled A, B and C symbols represent the maximum and minimum values of forging forces that exist during the variation in welding current levels, as shown in Figure 8(a). The dynamic resistances are therefore calculated within the welding current flow (10 cycles), and can be seen from an ascending-type sinusoidal waveform in the force profiles. The breakdowns (melt) between both metals are shown with triggers as an inter-melting situation (IMS).

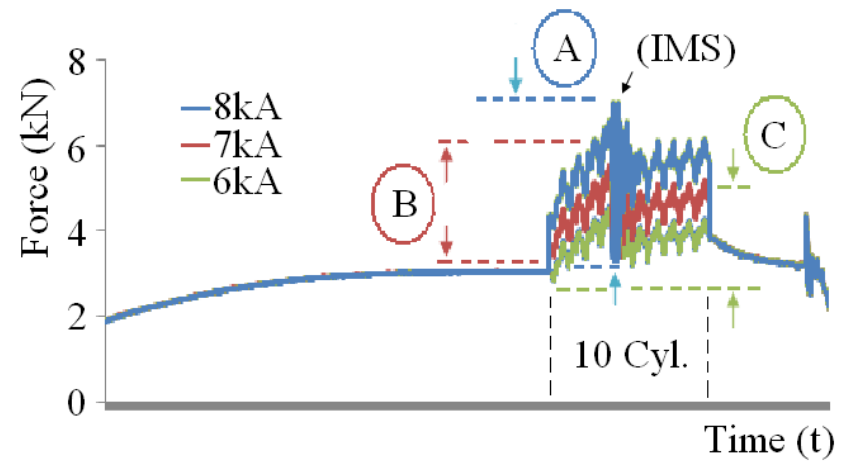

(a) Force profiles

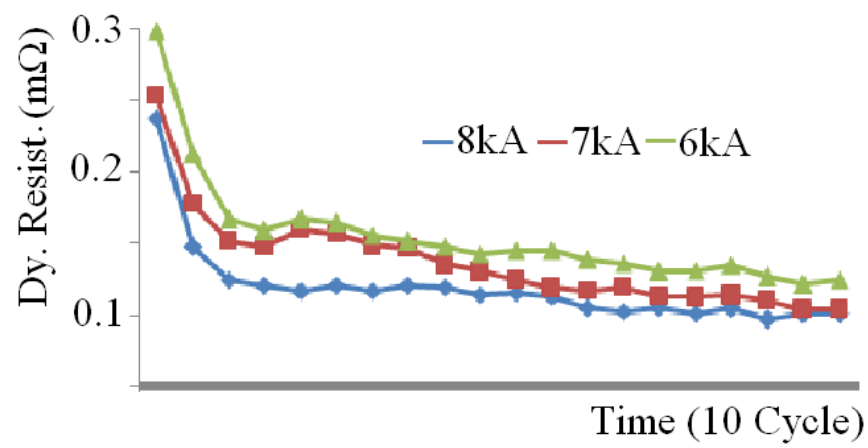

(b) Dynamic resistance

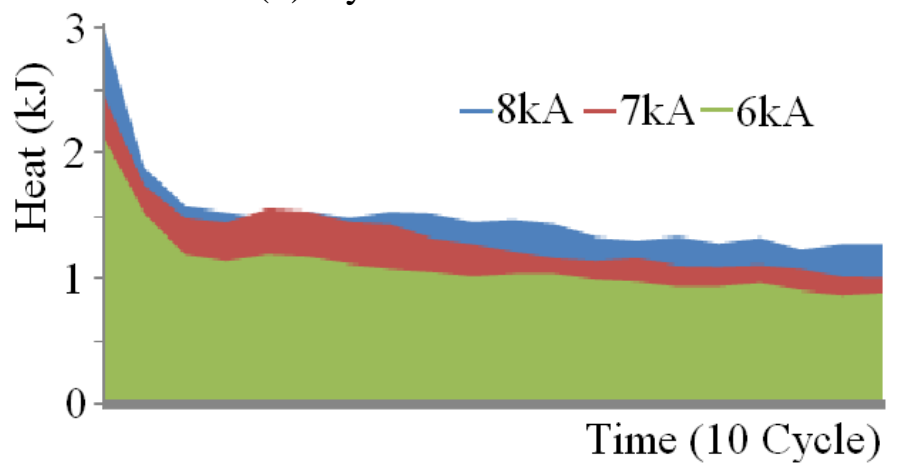

(c) Heat generations

Figure 8. Force profile, dynamic resistance and heat generation of various current levels. 
These resistive patterns have directly influenced the initial heat development, and also the heat distribution during fusion at the welded areas, as shown in Figure 8(c). This heat distributive pattern enables nugget growth, as it continues melting the outer region (solid or HAZ) of the molten areas; and this action continues proportionally in an omni-direction until the expulsion limit is reached (Tang et al., 2002). It was computed from the equation $\left(Q=I^{2} R t\right)$ that the weld time was $20 \mathrm{mS}$ for a 10 weld cycle; with currents of 6,7 and $8 \mathrm{kA}$ and the resistance $(R)$ was set according to the dynamic resistive changes. It is clearly seen that the dynamic resistive pattern more or less replicates the heat distributive patterns, as shown in Figure 8(c). For instance, when the current was increased from 6 to 7 and 7 to $8 \mathrm{kA}$, the dynamic resistances were slightly reduced but the initial heat developments were increased due to the multiplying factors of heat generation being formed from the time, resistance and current. Noticeably the drop in resistance $(\mathrm{m} \Omega)$ in this case was minimal but the current increment was sufficiently rapid, as it is multiplied by itself $\left(I^{2}\right)$ and therefore the heat developed rapidly. In other words, the current and heat increments were proportionally interrelated to each other (Figure 8(c)). When the starting heat was very high due to the joining surface resistance of the BMs (the faying surface between sheets), the melting initially started at the middle of the BMs and grew outwards in all directions for $20 \mathrm{mS}$. As a result, initial drops in resistances were seen at the beginning of the dynamic resistive curves for all $(6,7$ and $8 \mathrm{kA})$ welding processes due to the removal of surface contamination and/or the establishment of proper contacts with the surfaces of the BMs. Once the electrode-to-sheet contact resistances are well balanced, the bulk resistances of the BMs start to accumulate the thermal increments on both metals sheets, and consequently the initial melt starts at the contact areas of both metal sheets (asperities). When the melting point of the materials is reached at the asperities, the melting process immediately starts and consequently the heat travels outwards in all directions with an almost constant pattern of heat distribution, which kept melting the contact areas from the internal surfaces of BMs toward the electrode contact areas until the welding process is finished (Rinsei et al., 2006). Obviously, the electrical resistivity and thermal conductivity is purely dependant on the materials' properties, whereby the diameters of the molten areas are directly proportional to such heating effects. However the electrode forces holding the BMs together are not factor-free. They are directly exposed to forging forces due to the huge amount for electrons flowing, and produce vibrations because of the sinusoidal waveform of the current flow. This waveform is clearly seen in the force profiles (Figure 8(a) and Figure 9(a)) and the resulting porous induction during solidification.

On the other hand the resistive pattern slightly differed from Dickinson's model. By referring to Dickinson's dynamic resistive model, regions 3, 4 and 5 are flattened in this experiment rather than produce bell-like-curve growth. This occurred because of the forging forces that increased beyond the weld lobe regions. The pneumatic-based electrode actuation system does not produce constant forces, as the forging forces increase due to the huge amount of current flow (Table 2). Another situation was observed for the electrode pressing forces with a constant current $(6 \mathrm{kA})$. The force was increased in a few attempts, and consequently the resistances were changed. When the electrode pressing forces are raised from 3 to 4.5 and 4.5 to $6 \mathrm{kN}$, the resistances were slightly decreased due to the proper contact between electrodes and sheets. These changes have resulted in decrements in the heat and the margin reduction among various forces were too narrow in the heat distributions compared to the current increments (Chang, at al., 2006). Figure 9 shows the various forces applied during the 
welding process for a constant current ( $6 \mathrm{kA})$, the equivalent resistive changes and also the resulting heat distributions on the dissimilar steels.

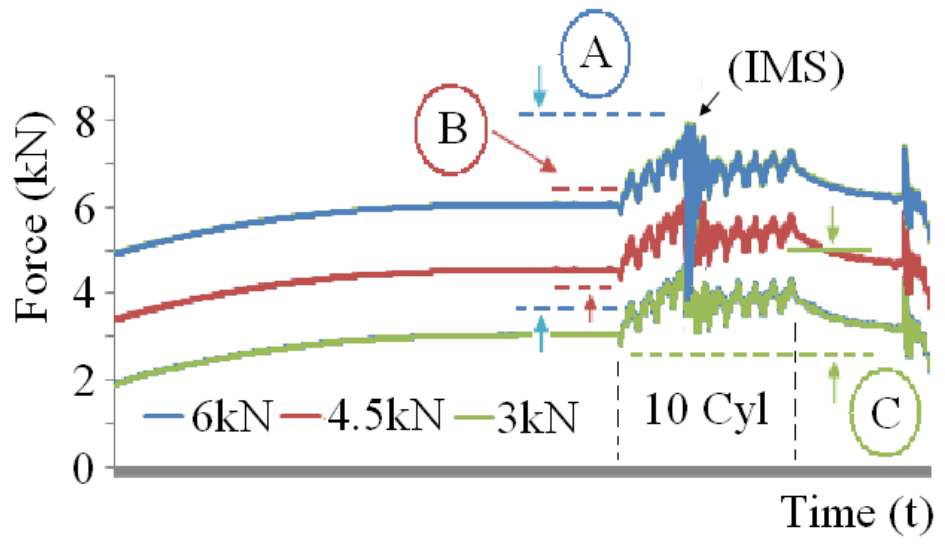

(a) Force profiles

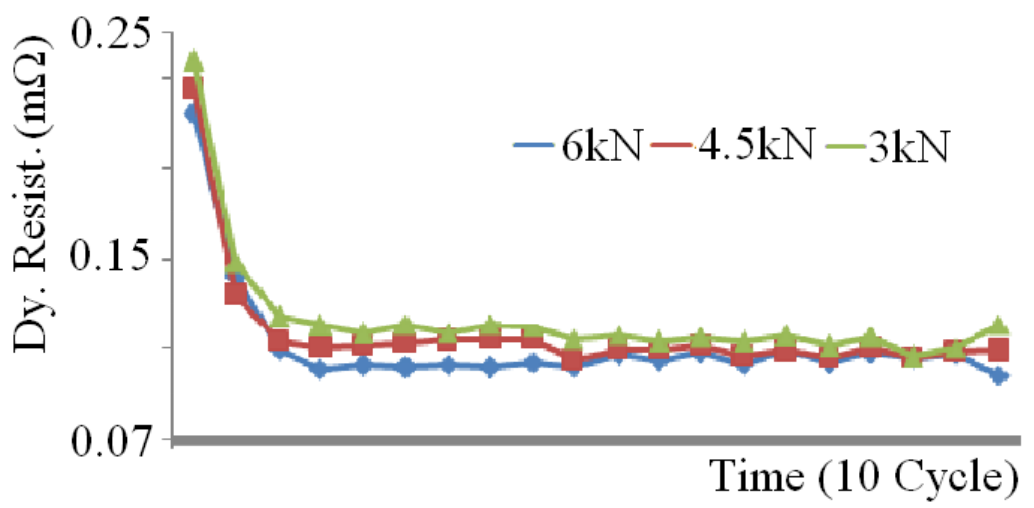

(b) Dynamic resistances

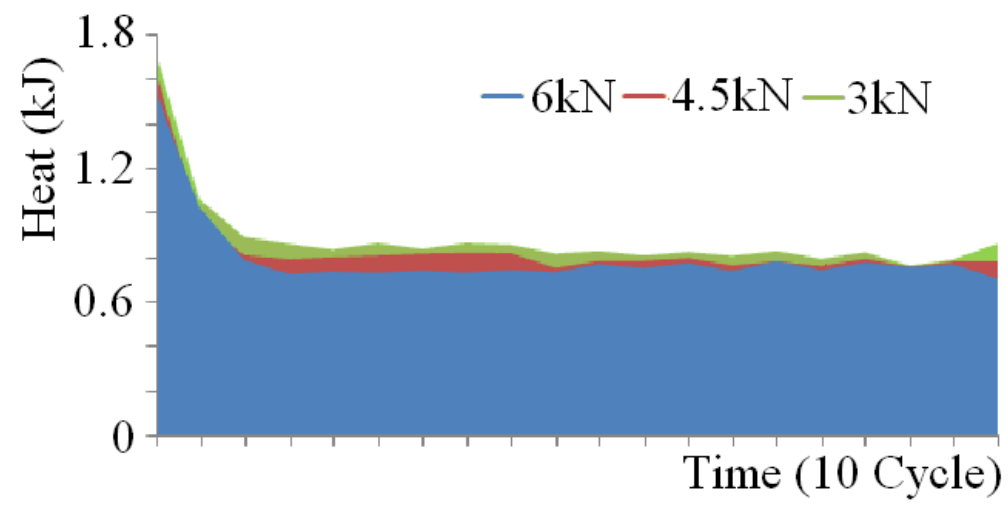

(c) Heat generation

Figure 9. Force profile, dynamic resistance and heat generation of various force profiles.

Table 2 summarises the overall variations in forging forces, dynamic resistances and also heat distributions according to the two basic parameter changes. It is clearly seen from the table that the current increments caused proportionally large heat increments, whereas the force increments caused a drop in heat during the welding 
process. The minimal and maximum values are listed to show the ranges of values determined for these changes.

Table 2. Forging force, dynamic resistance and heat distribution ranges.

\begin{tabular}{lllll}
\hline & Various currents & $8 \mathrm{kA}$ & $7 \mathrm{kA}$ & $6 \mathrm{kA}$ \\
Forging forces & Range $(\mathrm{kN})$ & 4 & 2.8 & 2.4 \\
& Various forces & $6 \mathrm{kN}$ & $4.5 \mathrm{kN}$ & $3 \mathrm{kN}$ \\
& Range $(\mathrm{kJ})$ & 2.5 & 2.4 & 2.4 \\
\hline \multirow{5}{*}{ Dynamic Resistance } & Various currents & $8 \mathrm{kA}$ & $7 \mathrm{kA}$ & $6 \mathrm{kA}$ \\
& Range $(\mathrm{m} \Omega)$ & $0.24-0.12$ & $0.26-0.21$ & $0.30-0.40$ \\
& Various forces & $6 \mathrm{kN}$ & $4.5 \mathrm{kN}$ & $3 \mathrm{kN}$ \\
& Range $(\mathrm{m} \Omega)$ & $0.22-0.10$ & $0.23-0.12$ & $0.24-0.13$ \\
\hline \multirow{5}{*}{ Heat Distribution } & Various currents & $8 \mathrm{kA}$ & $7 \mathrm{kA}$ & $6 \mathrm{kA}$ \\
& Range $(\mathrm{kJ})$ & $3.00-1.30$ & $2.40-1.00$ & $2.20-0.90$ \\
& Various forces & $6 \mathrm{kN}$ & $4.5 \mathrm{kN}$ & $3 \mathrm{kN}$ \\
& Range $(\mathrm{kJ})$ & $1.50-0.70$ & $1.55-0.80$ & $1.70-0.85$ \\
\hline
\end{tabular}

\section{Tensile Test Results}

In assessing the tensile-shear strength (Figure 10), a one hundred kiloNewton (100 kN) capacity machine was used to determine the loading force with respect to the welding process parameter variations. The crosshead speed was maintained at $70 \mathrm{~mm}$ per minute, and $30 \mathrm{~mm}$ of mechanical grip was applied at both ends. The pull to break test was conducted and the ultimate tensile strength (UTS) was taken as the maximum weld strength at which the weld joint crack initiation occurs. In some cases, post-cracking initiating propagation was analysed as separating both parent materials from each other. The average strength values from the five samples were taken as the equivalent strength of that particular weld schedule. Regarding the analysis of the weld schedules from 1 to 2 and 2 to 3; a strength increment was noted due to the increment in welding current from 6 to 7 and 7 to $8 \mathrm{kA}$ respectively. Obviously, this shows that an increase in current has occasioned in an increase in strength due to the resulting increment in diameter. Moreover the welded nuggets had an asymmetrical shape at the welded zone, and also a two-in-one diameter to represent the mixed steel joints.

Figure 11 shows the changes in diameter with respect to the welding current and electrode force changes on both sides. The stainless steel side nuggets were slightly wider and higher compared to thse on the carbon steel sides. However both sides have shown proportional changes. This fulfils the Joule's law of heating $\left(\mathrm{Q}=\mathrm{I}^{2} \mathrm{Rt}\right)$; where $Q$ represents the heat developed; $I$ represents the current; $R$ represent the resistance and $t$ represent time. By increasing the current, the heat supplied at the electrode tip is also proportionally increased and therefore the corresponding diameters increments were obtained. However when the electrode force incremental set is considered, the force increment has caused a drop in strength because of the drop in the total resistances. Regarding the increment in force from 3 to 4.5 and 4.5 to $6 \mathrm{kN}$; the tensile strength is reduced because the resistive components are reduced in the heating process, which is another proportional coefficient of the heat formula (Darwish and Al-Samhan, 2004). Thus the resistance is reduced by producing a high electrode pressing force as it creates 
a change in length $(\ell)$ which is a proportional coefficient of the resistance equation. The bulk resistance is computed as $R=\rho \ell / A$; where $\rho$ is the resistivity $\left(\mathrm{CS}=1.611 \times 10^{-7}\right.$ $\left.\Omega . \mathrm{m} ; \mathrm{SS}=6.89 \times 10^{-7} \Omega . \mathrm{m}\right) ; \ell$ is the length $(1 \mathrm{~mm}+1 \mathrm{~mm})$ and A is the contact area $\left(19.63 \mu^{2}\right)$ of the electrode. The electrode tips were not changed at all so that the resistance is mainly affected due to changes in the bulk resistance. Similar types of effect have also seen during the tensile tests, as reductions in weld diameters require lower loading effects (Kent et al., 2000).

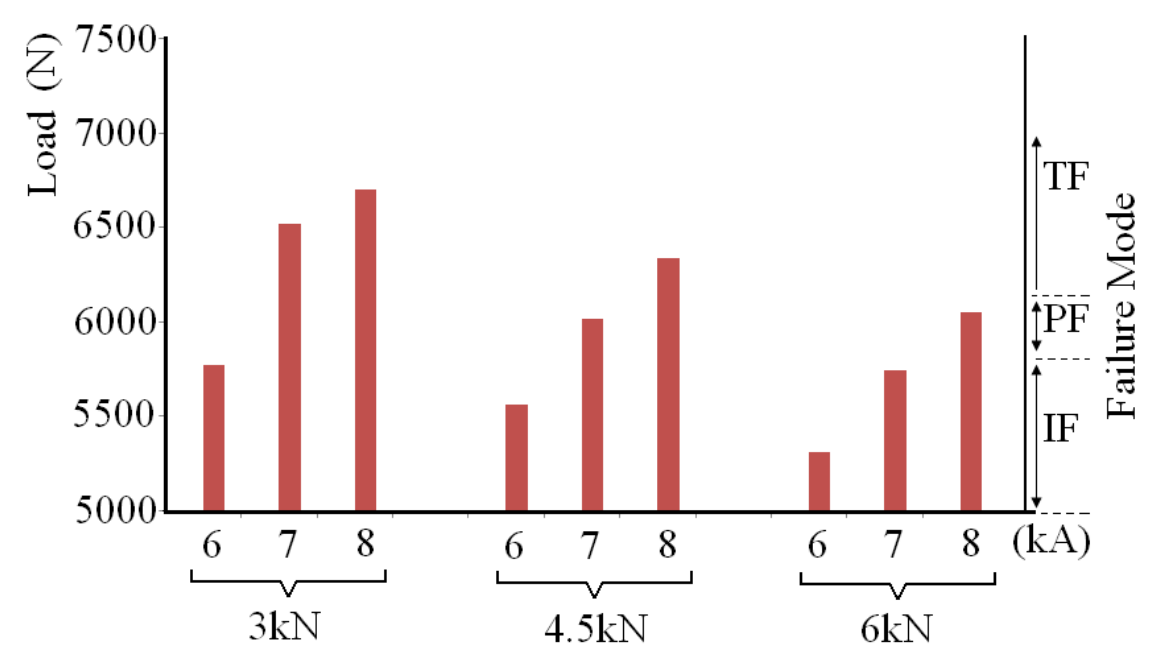

Figure 10. Tensile shear test results.

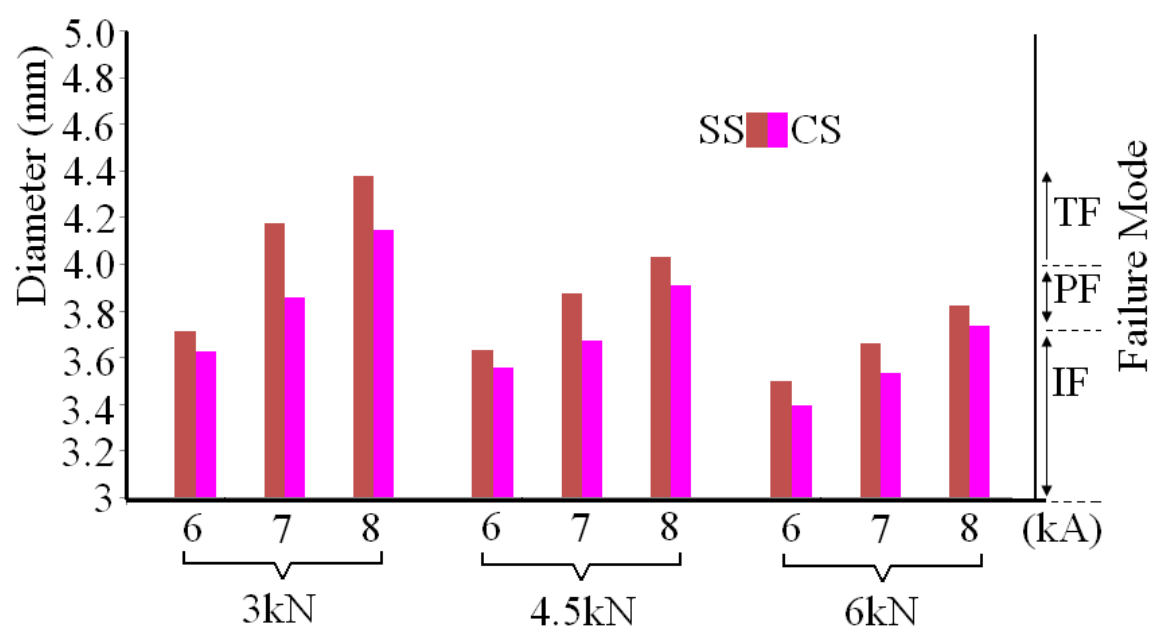

Figure 11. Diameter of weld nuggets and failure modes.

\section{Failure Modes}

Having considered the failure modes of the tensile tests of dissimilar joints, it has been noted that crack initiations occurred in accordance with weld type. A poor weld joint has an interfacial fracture (IF) (Figure 12(a)) and the loading force falls below $5.5 \mathrm{kN}$. The interfacial cracks occur in the middle welded regions due to poor bonds. A moderate-good weld has a complete crack in the BM (tear from one side) at the HAZ (PF) (Figure 12(b)), and the loading force falls between 5.5 to $6.3 \mathrm{kN}$. In dissimilar joints, crack initiation starts on the carbon steel side rather than the stainless steel side 
due to the difference in hardness. This occurred due to the metal strength as the strength of carbon steel is lower compared to stainless steel. Furthermore a good weld (Figure 12(c)) has better bonds between sheets and therefore requires a higher loading force to break the joint. In this case it was just above $6.3 \mathrm{kN}$, and the tear was a button pullout (TF) (Lee et al., 2004). Nevertheless, post-crack initiation propagation was carried out so that the difference between PF and TF can be observed; otherwise both failure modes will be treated in the same category which is what other fellow researchers have done before.

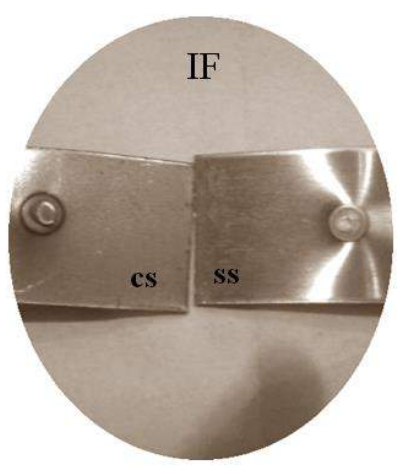

(a)

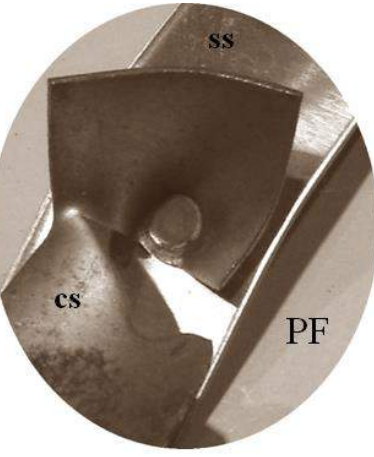

(b)

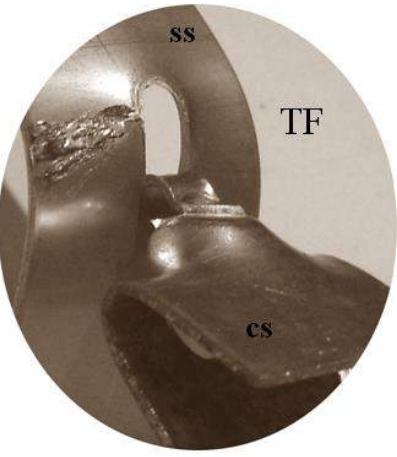

(c)

Figure 12. Crack initiation of failure modes.

\section{Indentation of Welded Areas}

The electrode pressing force is the root cause for the indentation of the welded areas. This force may create a situation of a splash out from the areas concerned when the nuggets' diameter grows beyond that of the electrode tip (encapsulation), which is always referred to as expulsion. However, the worst case (expulsion) scenarios were not conducted in these experiments. Figure 13(a) shows the upper and lower indentations created by the electrode pressing force during the welding process. Figure 13(b) shows micro indentations that occurred for both categories of parameter (welding current and electrode force) changes. It is obviously noted that the indentation is proportional to the welding current, as well as the electrode pressing force. As the parameters are increased, the indentation consequently becomes deeper on both sides of the BMs. In most cases the indentation was slightly higher on the upper electrode side because it creates a hitting impact due to the pneumatic cylinder during the squeeze cycles, while the lower electrode remains static. This pneumatic driven-electrode pressing force is not a constant force during or after the welding process takes place. It creates forging forces due to the huge current flow from upper electrode through the BMs to the lower electrode and vice versa. When the input welding current is sinusoidal, the direction of current flow follows in accordance to the different polarities of the waveforms. This action occurs 20 times for 10 cycles at the welded areas. Figures 8(a) and 9(a) show the typical force profiles for stainless and medium carbon steels when forging forces occurred, regardless of parameter changes. One of the demerits of the huge forging force is that it may lead to the existence of pores in the solidified zones. Figure 14 shows pores that exist for both categories of welding conditions. 


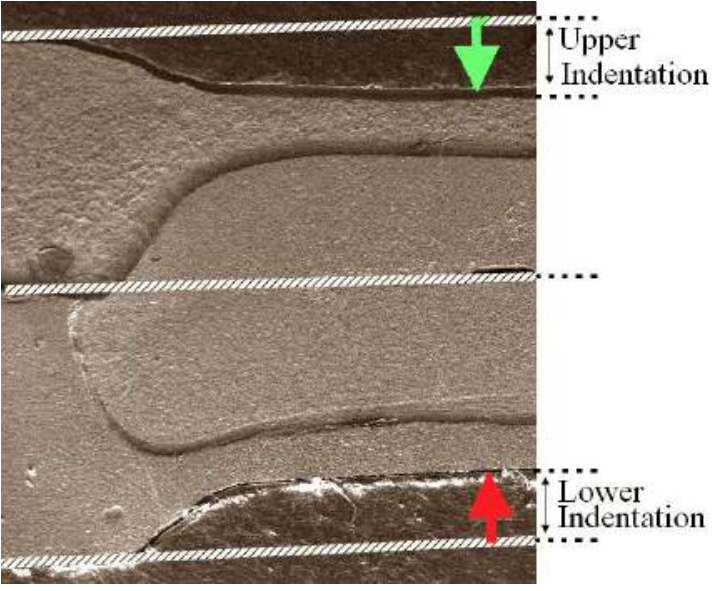

(a) Indentation of weld area indentations

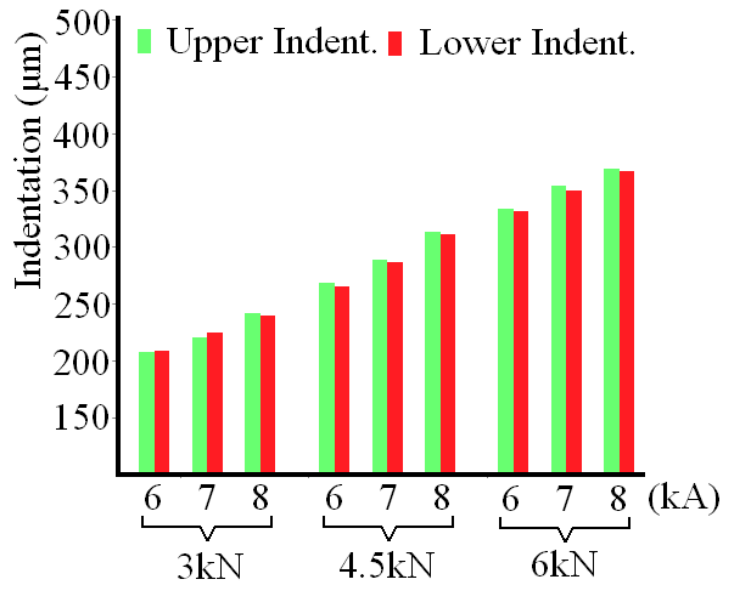

(b) Lower and upper micro

Figure 13. Indentation of welded areas for both categories of welding conditions

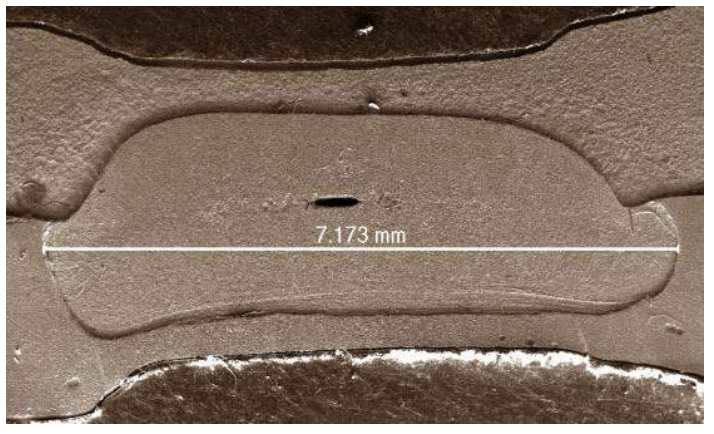

(a) Welding current

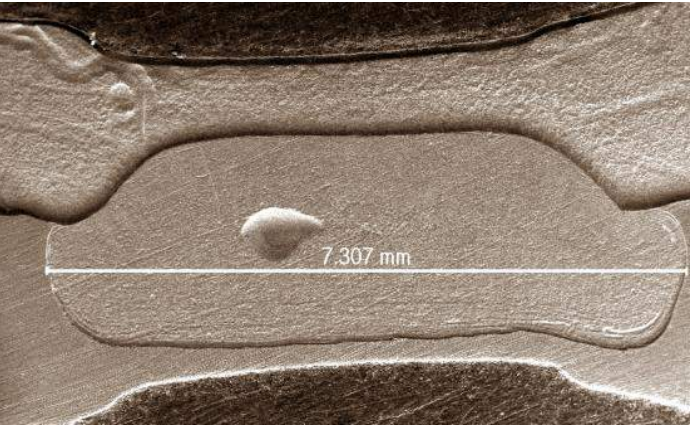

(b) Electrode force

Figure 14. Pore induced at welded zone .

\section{Hardness Test Results}

Regarding for the hardness test, the FZs seemed to comprise of asymmetrical joints. It has been slightly hardened on the stainless steel side (from 86 HRB to $115 \mathrm{HRB}$ ); and almost doubled (from $65 \mathrm{HRB}$ to $115 \mathrm{HRB}$ ) on the carbon steel side due to the solidification process (Nachimani, 2012b, c). However once the contact areas of both metals are molten, it becomes a dissimilar region and no longer a separate metal sheet. The HAZs' hardness was slightly lower (95 HRB for CS; 105 HRB for SS) than the FZ but higher than the BMs. However, the half-oval shape of the HAZs was easily noticeable on the carbon steel sides due to thermal conductivity. A similar region (HAZ) was not clearly seen on any stainless side, but the chances are high if the welding process is prolonged or nano-scaled (Huang et al., 2008). Figure 15 shows the zones that associated in the dissimilar weld joint. The hardness has been measured for all nine weld schedules, and is presented in Figure 16. 


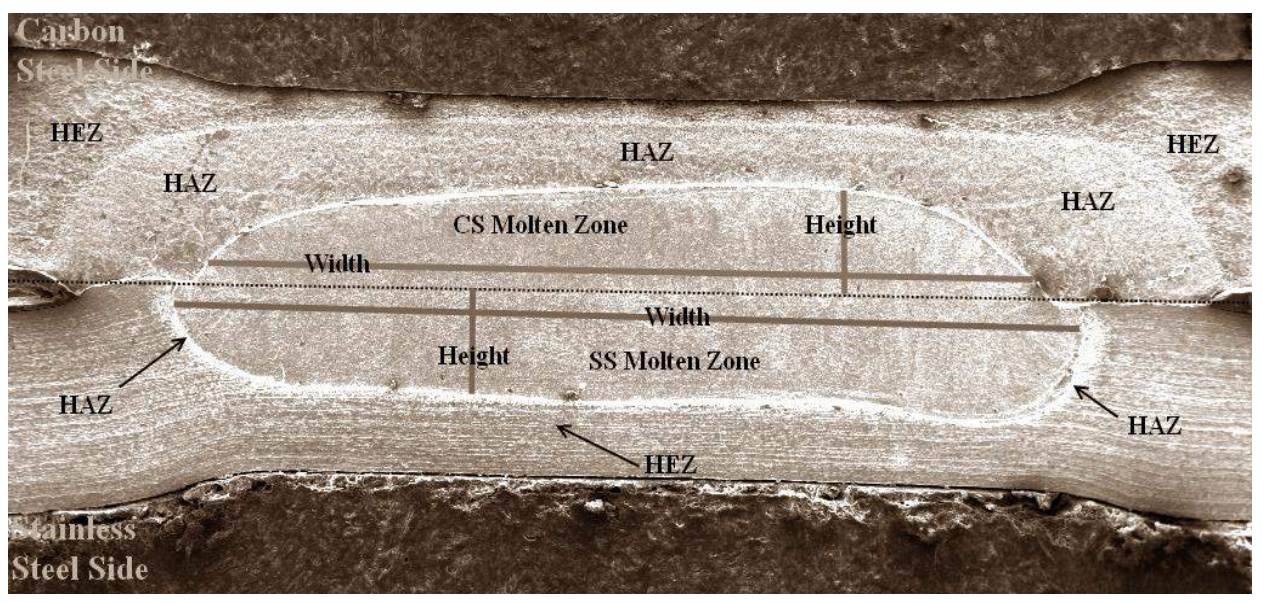

Figure 15. Dissimilar joint macro view.

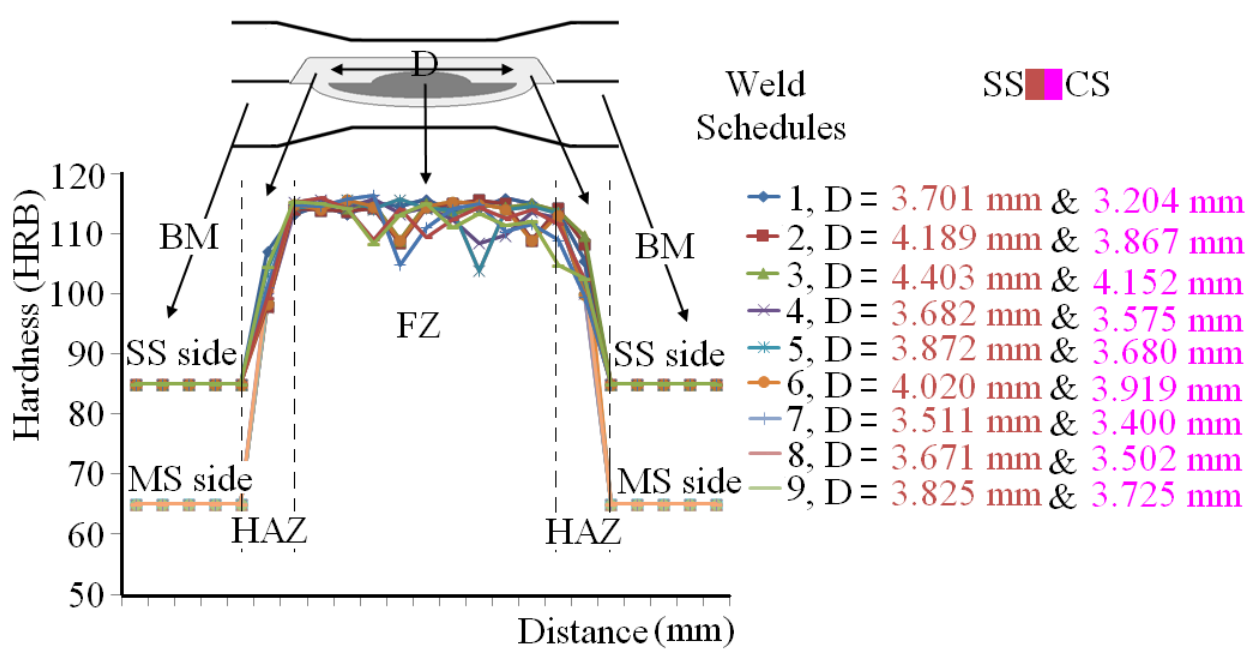

Figure 16. Hardness of dissimilar joint (weld schedule 1-9).

\section{Metallurgical Study}

Macro and micro structural observations are the heart of weld nugget analysis. It offers crystal clear information about the structural orientation of the weld nuggets and its surrounding area. A typical outlook of dissimilar FZs appears to be coarse grains, while the heat affected areas appear to be finer grains. The macrographs of these types of pattern have been noted throughout the experiment, and one of them is presented as Figure 16 as an example. Noticeably the parameter changes have directly influenced the grains in both zones: the FZs and the HAZs. However, the heat affected areas are not clearly visible on the stainless steel sides, and also vary from one weld schedule to another. Thus the thermal conductivity coefficients are higher in the carbon steels compared to the stainless steels, so wider ranges of HAZs were noted but the thermal expansion coefficient rate is lower in the carbon steel so that the width and height of the FZ was shorter $\left(4 \mathrm{t}^{0.5}\right)$ compared to the stainless steel. Head extended zones (HEZ) are also seen in some macro graphs, but they are still treated under HAZ. On the other side, the stainless steel seems to have a higher thermal expansion coefficient but lower thermal conductivity. So the HAZ was smaller but the FZ was wider $\left(5 \mathrm{t}^{0.5}\right)$ compared to the mild steels. Technically this phenomenon is called a heat imbalance during the 
welding process, and results in asymmetrical nugget formation. Table 3 lists the electrical, mechanical and thermal properties of the carbon and stainless steels. Furthermore, the original micro structural view of austenitic stainless steel (Figure 17(a)), which is made of Ferrite-Austenite-Martensite phases, becomes a martensitic structure when welded and solidified with a carbon steel sheet, as shown in Figure 17(b) (Khodabakhshi et al., 2011). On the other hand, the moderate pearlite of the carbon steel sheet (Figure 18) becomes a mainly martensite structure when mixed with austenitic stainless steel (Aravinthan and Nachimani, 2011b). The full martensite formation depends on the dilution ratio of the BMs. This dilution ratio can be observed in the hardness increment between the welded and unwelded regions of the BMs, or from the interfacial to pullout failures.

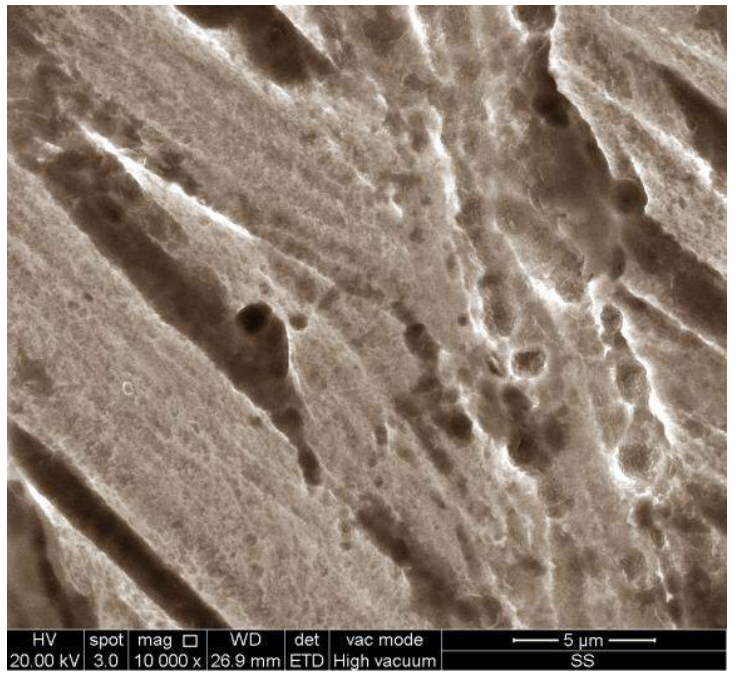

(a)

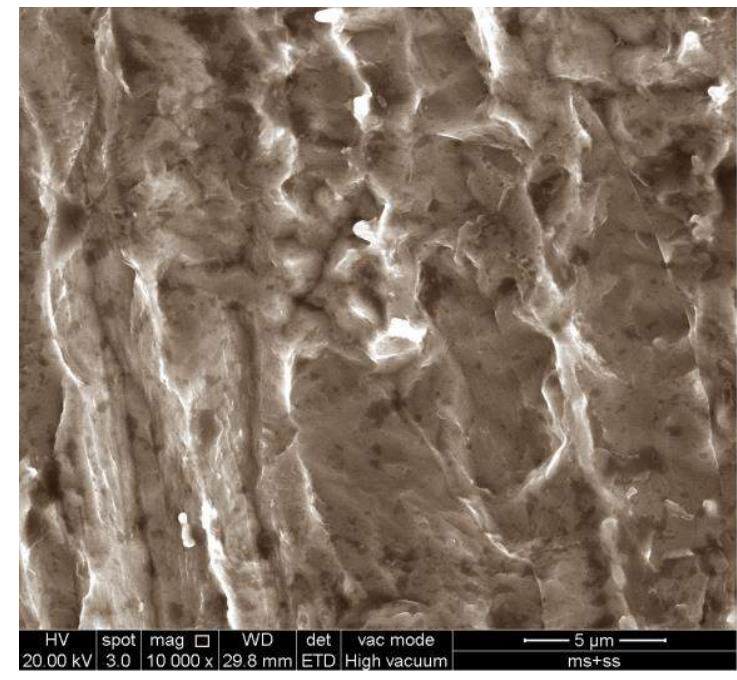

(b)

Figure 17. (a) Micro structural view of austenitic stainless steel (Ferrite-AusteniteMartensite phases); (b) Micro structural view of dissimilar steels (Martensite phase).

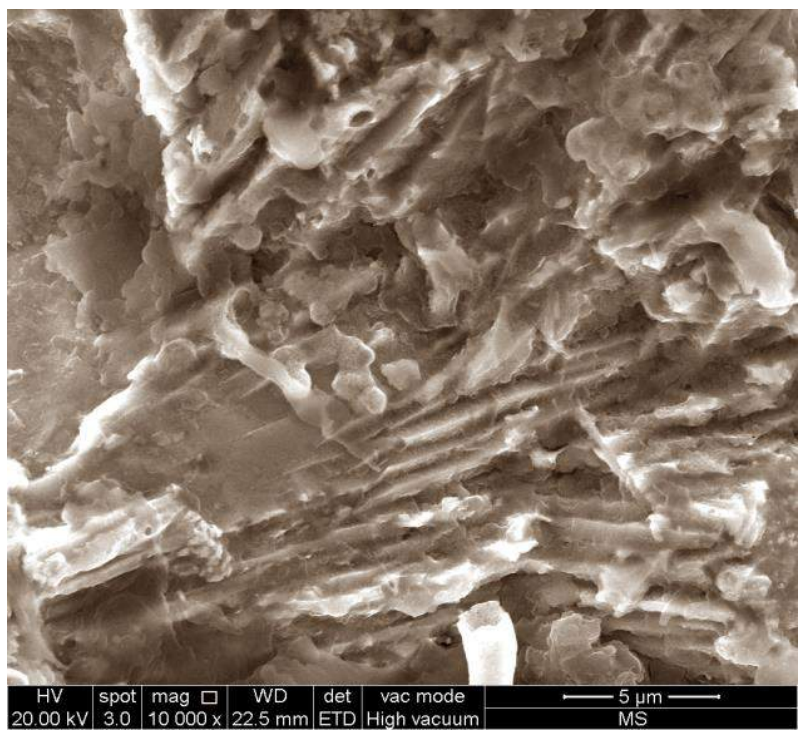

Figure 18. Micro structural view of carbon steel (Pearlite phase). 
Table 3. Electrical, mechanical and thermal properties of carbon and stainless steel.

\begin{tabular}{lll}
\hline Properties & Stainless steel & Carbon steel \\
\hline Density & $8.00 \mathrm{~g} / \mathrm{cm}^{3}$ & $7.85 \mathrm{~g} / \mathrm{cm}^{3}$ \\
Melting Point & $1400-1450^{\circ} \mathrm{C}$ & $1426-1538^{\circ} \mathrm{C}$ \\
Electrical Resistivity & $6.89 \times 10^{-7} \Omega . \mathrm{m}$ & $1.611 \times 10^{-7} \Omega . \mathrm{m}$ \\
Thermal Conductivity & $16.2 \mathrm{~W} / \mathrm{m} . \mathrm{K}(\mathrm{min})$ & $54 \mathrm{~W} / \mathrm{m} . \mathrm{K}(\mathrm{min})$ \\
Thermal Expansion & $17.2 \times 10^{-6} / \mathrm{K}$ & $12 \times 10^{-6} / \mathrm{K}$ \\
\hline
\end{tabular}

\section{CONCLUSION}

This experimental study examined the spot weld growth of welded joints containing carbon and stainless steel. The outcome of the research concludes that:

1. An increase in welding current to $8 \mathrm{kA}$ reduces the dynamic resistance, compared to 7 and $6 \mathrm{kA}$. However the heat generation proportionally increases with respect to current increments.

2. An increase in electrode pressing forces resulted in a decrement in dynamic resistance $(3,4.5$ and $6 \mathrm{kN})$; therefore resulting in a decrement in heat.

3. The poor dynamic resistive pattern of Dickinson was noted in this experiment due to high forging force fluctuations.

4. Micro indentations in the welded areas were proportional to the welding parameters of welding current and electrode pressing force.

5. The upper indentation appeared deeper due to pneumatic striking and the squeezing force on the surface of the upper BMs.

6. Pores not only existed due to high currents and long welding times, but also as a result of high forging forces.

7. An increase in welding current within the welding lobe resulted in an increment in the diameter of the weld nuggets. Therefore the increment in loading force during the tensile test was observed.

8. An increase in electrode pressing force resulted in a decrement in the diameter of the weld nuggets, and therefore a decrement in loading force during the tensile test was observed.

9. The three common post-crack failure modes were seen: since poor welds produce IFs; medium welds produce a tear from one side; and a good weld produces button pullout or tearing from both sides.

10. The micro structure clearly exhibits coarser grains in the FZ, refined grains in the $\mathrm{HAZ}$ and unchanged grains in the BM.

11. The hardness values of the welded areas increased from 65 to $115 \mathrm{HRB}$ on average on the carbon steel side, while stainless steel presented values of 86 to 115 HRB. This occurred due to phase changes from moderate pearlite to mainly martensite.

\section{ACKNOWLEDGEMENTS}

I would like to thank the Ministry of Science, Technology and Innovation of Malaysia (MOSTI) for its financial support throughout the experiments. 


\section{REFERENCES}

Aravinthan A. and Nachimani C. 2011a. Analysis of spot weld growth on mild and stainless steel. Welding Journal, August: 143-147.

Aravinthan, A and Nachimani, C. 2011b. Metallurgical study of spot welds growth on mild steel with $1 \mathrm{~mm}$ and $2 \mathrm{~mm}$ thicknesses. Journal of the Institution of Engineers, Malaysia, 72: 36-42.

Chang, B.H., Zhou, Y., Wang, Z., Heidarzadeh, F., Du, D. and Sui, B. 2006. Effect of forging force on fatigue behavior of spot welded joints of aluminum alloy 5182. Journal of Manufacturing Science and Engineering, 129(1): 95-100.

Darwish, S.M. and Al-Samhan, A.M. 2004 Peel and shear strength of spot-welded and weld-bonded dissimilar thickness joints. Journal of Materials Processing Technology, 147: 63-78.

Guocheng, X., Ling, W., Chun S.W. and Xiaoqi, Z. 2009. Quality monitoring for resistance spot welding using dynamic signals. Proceedings of the IEEE International Conference on Mechatronics and Automation, pp. 135-143.

Huang, F.X., Wang, X., Zhang, J., and Fang, Y. 2008. In situ observation of solidification process of AISI 304 austenitic stainless steel. Journal of Iron and Steel Research, 15(6): 78-82.

Kent, P., Von. M. and Henning, E.N. 2000. Comparison of peel bond and shear tensile test methods for needle punched geo synthetic clay liners. Geotextiles and Geomembranes, 18: 203-214.

Khodabakhshi, F., Kazeminezhad, M. and Kokabi, A.H. 2011. Mechanical properties and microstructure of resistance spot welded severely deformed low carbon steel. Materials Science and Engineering A, 389: 171-180.

Lee, W.S., Cheng J.I., and Lin C.F. 2004. Deformation and failure response of 304L stainless steel SMAW joint under dynamic shear loading. Materials Science and Engineering A, 381: 206-215.

Li. R.X. and Lei, X.C. 2011. Analyzing system of electric signals in spot welding process. International Conference on Electronic \& Mechanical Engineering and Information Technology, pp. 78-84.

Mehdi, M.H., Abadi, A. and Pouranvari, M. 2008. Correlation between macro/micro structure and mechanical properties of dissimilar RSW of AISI 304 austenitic stainless steel and AISI 1008 low carbon steel. Scientific paper of Association of Metallurgical Engineers of Serbia, 2: 56-63.

Nachimani, C. 2012a. Effects of electrode deformation on 304 austenitic stainless steel weld geometry of resistance spot welding. Journal of Mechanical Engineering and Sciences, 2: 261-270.

Nachimani, C. 2012b. Spot weld growth on 304L austenitic stainless steel for equal and unequal thicknesses. Caspian Journal of Applied Sciences Research, 1(11): 7987.

Nachimani, C. 2012c. Effects of electrode deformation on 304 austenitic stainless steel weld geometry of resistance spot welding. Journal of Mechanical Engineering and Sciences, 3: 261-270.

Rinsei, I.A. Ikeda, R., Okita, Y. and Ono, M. 2006. Development of advanced resistance spot welding process using control of electrode force and welding current during welding. Journal of the Japan Welding Society, 28(1): 141-148. 
Shih, F.L., Li, X.W., Yoke, R.W. and Dong, N.L. 2010. Input electrical impedance as quality monitoring signature for characterizing resistance spot welding. NDT\&E International, 43: 200-205.

Tang, H., Hou W., and $\mathrm{Hu}$ S.J 2002. Forging force in resistance spot welding. Proceedings of the Institution of Mechanical Engineers, Part B: Journal of Engineering Manufacture, 216: 957-969. 